\title{
Lipase-catalyzed modification of the flavor profiles in recombined skim milk products by enriching the volatile components
}

\author{
X. M. Zhang, ${ }^{*}$ N. S. Ai, $†$ J. Wang, $\dagger^{1}$ L. J. Tong, † F. P. Zheng, $\ddagger$ and B. G. Sun $\S^{1}$ \\ ${ }^{*}$ College of Food Engineering and Biotechnology, Tianjin University of Science and Technology, Tianjin 300457, P. R. China \\ †School of Food Science and Chemical Engineering, and \\ łBeijing Key Laboratory of Flavor Chemistry, and \\ §Beijing Engineering and Technology Research Center of Food Additives, Beijing Technology and Business University, 11 Fucheng Road, \\ Beijing 100048, P. R. China
}

\section{ABSTRACT}

The purpose of this study was to modify the amount and composition of volatile components in bovine milk products, in an attempt to create a recombined skim milk product with full-fat milk flavor but with only $0.5 \%$ fat. The experimental plan included lipasecatalyzed hydrolysis and esterification reactions using Palatase 20000L (Novozymes, Bagsværd, Denmark). The results, measured by the methods of volatile compositional analysis and sensory evaluation, showed that the flavor profiles of the optimal recombined milk products were effectively modified in this way, possessing intensified characteristic volatile flavor components with rather low level of fat contents, and the sensory characters were quite realistic to natural whole milk flavor.

Key words: lipase hydrolysis, lipase esterification, milk volatile, skim milk flavor modification

\section{INTRODUCTION}

Bovine milk products, which possess a balanced nutritious composition, are regarded as convenient and beneficial foods for adults and infants. Bovine whole milk contains nutrients suitable for the human body in a natural form, making it one of the healthiest whole foods (Lubary et al., 2010a). Whole milk has a pleasant flavor but carries a perception of being high in fat. In contrast, the flavor character of skim milk is considered deficient by some consumers because of insufficient intensities of aroma and taste, but the amount of fat present is lower (Karagül-Yüceer et al., 2004). In terms of compositional variance, this obvious sensory distinction between whole milk and skim milk is presumably due to the difference in fat amount.

\footnotetext{
Received December 16, 2015.

Accepted July 6, 2016.

${ }^{1}$ Corresponding authors: wangjing@th.btbu.edu.cn and sunbg@ btbu.edu.cn
}

The authentic flavor of certain foodstuffs derives from their origin, and lipids have a dominating influence on the formation and preservation of natural milk flavor (Lock and Bauman, 2004); whole milk and single cream may be ideal substances by which authentic natural-milk flavor can be intensified. In natural bovine whole milk, short-chain fatty acids $\left(\mathrm{C}_{2}\right.$ to $\mathrm{C}_{14}$, SCFA) originate from triacylglycerols (TAG), which make up over $98 \%$ of milk fat, mainly distributed at the $s n-1$ and $s n-3$ positions of the glycerol backbones connected by ester bonds (Bourlieu et al., 2009; Lubary et al., 2010b). We can assume that SCFA are common volatile flavor components of natural whole milk because of their easy release from TAG by means of internal or external factors, such as endogenous enzymes, pasteurization, and so on. Some SCFA contribute to the characteristic flavor of milk when present at low levels (Regado et al., 2007; Kalač and Samková, 2010). However, greater SCFA release is not generally a positive attribute because of the development of unpleasant rancid off-flavors. Meanwhile, the manipulation of SCFA can produce other kinds of compounds that consume excessive SCFA and producing other volatiles to compensate for rancid offflavors (Campbell and Drake, 2013; Cao et al., 2014).

Palatase 20000L (EC 3.1.1.3, Novozymes, Bagsværd, Denmark), an $s n$-1,3-regiospecific lipase, can hydrolyze TAG of milk fat exclusively at the $s n-1$ and $s n-3$ positions, and thus release more free SCFA, enhancing the amount and proportion of this common kind of volatile portion from milk fat (Bourlieu et al., 2012). In many reports, Palatase 20000L has been shown to be the optimal lipase for enzymatic reactions in many kinds of milk products and other food substrates because of its wide applicability, easy operation, and environmental benefits (Wang and Xu, 2009; Kurtovic et al., 2011; Tan et al., 2011). Furthermore, Palatase 20000L can catalyze esterification reaction for its transesterification effect. Esterification of SCFA with ethanol, a process known as ethanolysis, not only releases free SCFA at maximum efficiency in suitable conditions, but also synthesizes fatty acid ethyl esters (FAEE) in consider- 
able amounts (Lubary et al., 2010c). The generation of FAEE can consume the free SCFA hydrolyzed from TAG, promoting the hydrolysis reaction to a more thorough extent. Moreover, this moderate enhancement of FAEE is feasible when excessive SCFA are released because FAEE initially exist in natural bovine whole milk (Lubary et al., 2009; Villeneuve et al., 2013). The FAEE present a lightly sweet fruit flavor with lower thresholds than the corresponding SCFA. The generation of FAEE can dilute the undesirable rancid flavor caused by overproduction of SCFA. However, high levels of such FAEE can lead to a fruity flavor defect that might cover up the true flavor of milk (Shojaei et al., 2006). The lipase-catalyzed modification of bovine milk fat to improve the flavor quality of recombined skim milk has been poorly documented in recent years; therefore, further relevant research is necessary to evaluate the effect of milk fat alteration on milk volatiles, including SCFA and FAEE.

Hence, lipase reactions of whole milk and single cream, including hydrolysis and esterification (ethanolysis) reactions, were applied as the experimental scheme in this study, and Palatase 20000L was the lipase used in lipase-catalyzed reactions to create a bovine milk product of satisfying milk flavor and lower fat. We used volatile composition analysis and sensory evaluation to estimate and compare the flavor qualities of the testing samples.

\section{MATERIALS AND METHODS}

\section{Samples and Reagents}

Whole milk (fat content: 3.3-3.8\%), skim milk (fat content: $\leq 0.5 \%$ ), and single cream (fat content: $\sim 40 \%$ ) were obtained from Beijing Sanyuan Group (Beijing, China). All milk samples, which were supplied by the same farm in a 2-d period to ensure initial consistency, were pasteurized $\left(85^{\circ} \mathrm{C}, 15 \mathrm{~s}\right)$ before use and stored at $4^{\circ} \mathrm{C}$. Palatase 20000L (EC 3.1.1.3, in liquid form, Novozymes), produced from Rhizomucor miehei, was the lipase used based on previous studies (Sun et al., 2012). The catalysis activity of Palatase 20000L was measured every 2 mo during the experimental period. 1,2-Dichlorobenzene (HPLC grade, Beijing Chemical Reagents Company, Beijing, China) was used as the internal standard. All other chemicals and reagents were of analytical grade.

\section{Activity Test of Palatase 20000 L}

The activity of Palatase 20000L was measured on a model emulsion of olive oil by monitoring titratable free fatty acids (FFA) released by hydrolysis of the olive oil substrate. Considering the different matrices of whole milk and single cream, together with the versatile applicability of Palatase 20000L, olive oil was selected as an independent and impartial substrate for the lipase activity assay.

Phosphate buffer ( $8 \mathrm{~mL}, \mathrm{pH} 7.5,0.05 \mathrm{~mol} / \mathrm{L})$ and polyvinyl alcohol (2\%)-olive oil emulsion (8 mL; 3:1, $\mathrm{vol} / \mathrm{vol}$ ) were mixed in a $100-\mathrm{mL}$ flask and heated at $37^{\circ} \mathrm{C}$ for $10 \mathrm{~min}$. Then, $100 \mu \mathrm{L}$ of Palatase $20000 \mathrm{~L}$ was added into the flask. The whole system was stirred magnetically at 30 revolutions/s for $20 \mathrm{~min}$. Finally, ethanol $(95 \%, 30 \mathrm{~mL})$ was dissolved into the mixture to terminate the reaction. A standard solution of $\mathrm{NaOH}$ $(0.05 \mathrm{~mol} / \mathrm{L})$ was used to titrate the hydrolyzed free acid. The lipase activity units were defined as follows: 1 unit equals the amount of Palatase 20000L consumed to generate 1 micromole of FFA per minute (Wang and $\mathrm{Xu}, 2009)$.

\section{Lipase-Catalyzed Model System Experimental Details}

In the lipase-catalyzed model system of whole milk or single cream, a 2-step process was adopted according to former reports and our previous findings (Sun et al., 2013). The 2-step process involved a lipase hydrolysis reaction and lipase esterification reaction, which allowed higher efficiency of target compound synthesis in a solvent-free system.

The experimental protocol of the lipase-catalyzed model system was as follows (as illustrated in Figure 1):

(1) lipase hydrolysis reaction: the reaction system was composed of bovine whole milk (or single cream) and lipase, and the samples were measured by acid value (AV) and headspace solidphase microextraction (HS-SPME) GC-MS analysis;

(2) lipase esterification reaction: the reaction system was composed of hydrolyzed whole milk (or single cream), lipase, and ethanol, and the samples were evaluated by HS-SPME-GC-MS analysis for volatile composition;

(3) preparation of recombined milk products of PCM and $\mathrm{PCC}(\mathbf{P C M}=$ recombined milk product composed of $100 \mathrm{~mL}$ of skim milk and the upper layer from $25 \mathrm{~mL}$ of esterified whole milk; PCC $=$ recombined milk product composed of $100 \mathrm{~mL}$ of skim milk and $2 \mathrm{~g}$ of the upper layer from esterified single cream);

(4) preparation of 4 "better" PCM and 4 "better" PCC. Using HS-SPME-GC-MS analysis and preliminary sensory analysis, 4 better PCM or PCC were primarily selected according to the 4 
whole milk / single cream $\stackrel{\text { Palatase } 20000 \mathrm{~L}}{\longrightarrow}$ hydrolyzed whole milk / single cream $\frac{\text { Palatase } 20000 \mathrm{~L}+\text { ethanol }}{\text { volatiles yield }(\mathrm{AV}, \mathrm{GC} / \mathrm{MS})}$ esterified whole milk / single cream

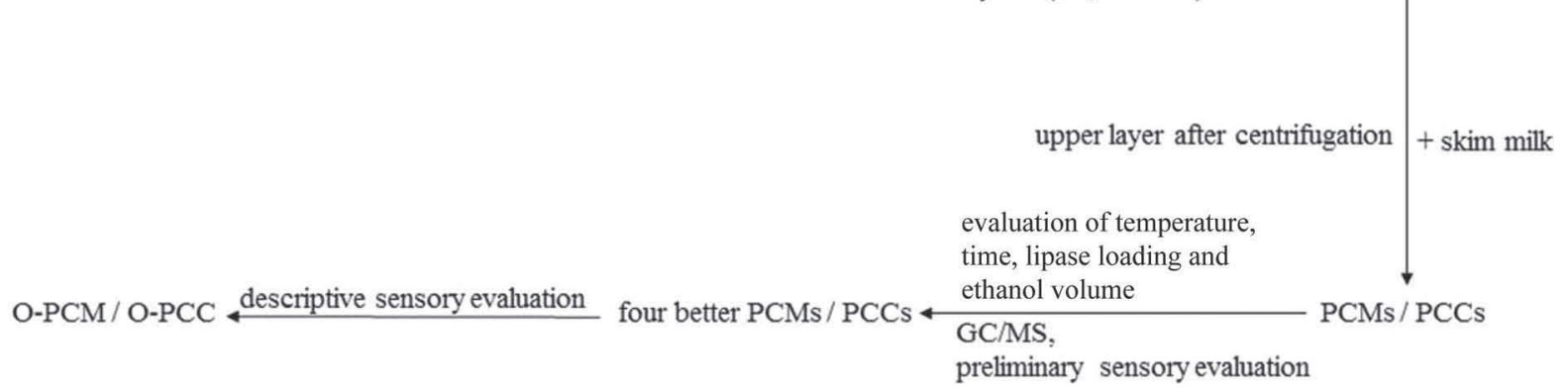

Figure 1. Flow diagram depicting the process of the lipase-catalysis treatments for the preparation of the recombined milk products from whole milk or single cream. $\mathrm{AV}=$ acid value; $\mathrm{PCM}=$ recombined milk product composed of skim milk $(100 \mathrm{~mL})$ and all of the upper layer from esterified whole milk $(25 \mathrm{~mL}) ; \mathrm{PCC}=$ recombined milk product composed of skim milk $(100 \mathrm{~mL})$ and upper layer $(2 \mathrm{~g})$ of esterified single cream; O-PCM and O-PCC = PCM and PCC acquired under optimal conditions.

parameters (i.e., temperature, time, lipase loading, and ethanol volume) of lipase esterification reactions;

(5) preparation of O-PCM and O-PCC: by further descriptive sensory analysis of 4 better $\mathrm{PCM}$ or 4 better PCC, 1 optimal PCM (O-PCM) and PCC (O-PCC) were selected from the 4 better PCM and PCC according to the descriptive sensory scores, which were analyzed by HS-SPMEGC-MS and compositional analysis.

Lipase Hydrolysis Reaction. To improve efficiency of lipase hydrolysis, 3 experimental parameters, including hydrolysis temperature, hydrolysis time, and lipase loading, were optimized respectively in appropriate ranges. The total FFA and volatile SCFA were measured at the end of the reaction as indicators of the degree of hydrolysis.

Lipase Esterification Reaction. After the lipase hydrolysis experiment, the lipase esterification process was adopted to achieve better milk aroma and flavor. Different amounts of lipase and ethanol were added to hydrolyzed samples of milk or single cream, reacting at different temperatures and times before the reactions were stopped by heating for 3 to $5 \mathrm{~min}$ at $80^{\circ} \mathrm{C}$ to deactivate the remaining lipase. After lipase esterification reactions, every sample from esterified whole milk or single cream was subjected to centrifugation at $6,720 \times$ $g$ at $10^{\circ} \mathrm{C}$ for $10 \mathrm{~min}$. Then, the whole upper layer of the 25 -mL esterified whole milk sample or $2 \mathrm{~g}$ of the upper layer of the esterified single cream sample was added to skim milk $(100 \mathrm{~mL})$ and stirred at 1,000 rpm for 2 min. Through these procedures, a PCM or PCC was prepared for the following analysis. Four experimental parameters - esterification temperature, esterification time, lipase loading, and ethanol volume - were optimized respectively from the appropriate ranges deter- mined before the experiment. The effect of lipase esterification was assessed by HS-SPME-GC-MS for volatile profile and preliminary sensory evaluation of PCM and PCC, measuring the sensory values of these recombined milk products. We set basic reaction conditions (whole milk model system: $35^{\circ} \mathrm{C}, 2 \mathrm{~h}, 0.8 \mathrm{U} / \mathrm{mL}$ of lipase, 0.8 $\mu \mathrm{L} / \mathrm{mL}$ of ethanol; single cream model system: $55^{\circ} \mathrm{C}, 2$ $\mathrm{h}, 3.7 \mathrm{U} / \mathrm{mL}$ of lipase, $1.0 \mu \mathrm{L} / \mathrm{mL}$ of ethanol) after the single parameter optimizations in this part, based on pre-experiment results, to further optimize the models; that is, one parameter was changed according to single parameter optimization and the other 3 remained the same. Thus, 4 better conditions ( 4 better PCM or PCC conditions) were acquired, as illustrated in Table 1 , and the corresponding samples were labeled randomly as samples 1 to 4 . Then, one sample was chosen as the optimal condition (O-PCM or O-PCC condition) based on the descriptive sensory scores.

\section{Lipase-Catalyzed Sample Analysis}

Acid Value Analysis. Acid value was measured to detect the total FFA generated after the hydrolysis reaction. Hydrolyzed whole milk (5 g) or hydrolyzed single cream $(3 \mathrm{~g})$ with a neutral solution of diethyl ether-ethanol $\left(\mathrm{V}_{\text {diethyl ether }}: \mathrm{V}_{\text {ethanol }}=2: 1,50 \mathrm{~mL}\right)$ was injected into a $250-\mathrm{mL}$ flask. After shaking the mixture to dissolve entirely and phenolphthalein indicator added, a standard solution of $\mathrm{KOH}(0.1 \mathrm{~mol} / \mathrm{L})$ was prepared to titrate the total FFA (Hedegaard et al., 2006). The AV was calculated by Equation [1]:

$$
\operatorname{AV}\left(\mathrm{mg}_{\mathrm{KOH}} / \mathrm{g}_{\text {sample }}\right)=\frac{\mathrm{V} \times \mathrm{N} \times \mathrm{M}}{\mathrm{W}}
$$

where $\mathrm{V}$ is the volume consumed of $\mathrm{KOH}$ standard solution $(\mathrm{mL}), \mathrm{N}$ is the concentration of $\mathrm{KOH}$ standard 
solution $(\mathrm{mol} / \mathrm{L}), \mathrm{W}$ is the weight of the sample $(\mathrm{g})$, and $\mathrm{M}$ is the relative molecular mass of $\mathrm{KOH}$.

$\boldsymbol{H} \boldsymbol{S}$-SPME-GC-MS Analysis. The purpose of the HS-SPME-GC-MS analysis was to detect volatile components in the milk samples. The SPME device and fibers, which were $75-\mu \mathrm{m}$ carboxen/PDMS (CAR/PDMS), $85-\mu \mathrm{m}$ polyacrylate (PA), 100- $\mu \mathrm{m}$ polydimethylsiloxane (PDMS), 65- $\mu \mathrm{m}$ PDMS/divinylbenzene (PDMS/DVB), and 50-/30- $\mu \mathrm{m}$ DVB/CAR/ PDMS, were purchased from Supelco Inc. (Bellefonte, PA). A catalyzed sample of whole milk or single cream $(10 \mathrm{~mL})$ was extracted into a $20-\mathrm{mL}$ vial, which was tightly capped with a polytetrafluoroethylene septum, with sodium chloride $(2 \mathrm{~g})$ added. After the sample was stirred at $40^{\circ} \mathrm{C}$ for $30 \mathrm{~min}$, the SPME needle was inserted and the fiber ( $5 \mathrm{~mm}$ above the liquid surface) was exposed to milk sample for 30 min to extract volatile compounds. When the SPME course finished, the fiber was retracted and inserted into the GC-MS injector port for desorption ( $5 \mathrm{~min}$ ).

Volatile profiles of the catalyzed milk samples were detected on a gas chromatograph-mass spectrometer (7890A/5975C), equipped with a DB-WAX capillary column $(30 \times 0.25 \mathrm{~mm} \times 0.25 \mu \mathrm{m}$; all from Agilent Technologies Inc., Palo Alto, CA). The injection was made in splitless mode at $250^{\circ} \mathrm{C}$. The temperature program was set as follows: the initial time was programmed at $50^{\circ} \mathrm{C}$ and held for $1 \mathrm{~min}$, then increased at $5^{\circ} \mathrm{C} / \mathrm{min}$ to $240^{\circ} \mathrm{C}$, and maintained $240^{\circ} \mathrm{C}$ for $1 \mathrm{~min}$. Helium was used as the carrier gas at the flow rate of $1 \mathrm{~mL} / \mathrm{min}$. The temperature of ion source was $230^{\circ} \mathrm{C}$ and the interface was $280^{\circ} \mathrm{C}$. The mass scan parameters included electron impact ionization voltage of $70 \mathrm{eV}$ and mass range of 20 to $350 \mathrm{~m} / z$.

Volatile compounds were identified by comparison of their mass spectra with the standard spectra provided by the National Institute of Standards and Technology (NIST11) database (Agilent Technologies Inc.), retention indices $(\mathbf{R I})$, which were calculated by using the retention data of linear alkanes $\mathrm{C}_{6}-\mathrm{C}_{30}$, and comparison with authentic chemicals to further confirm the identification. Quantification of the identified volatile compounds was calculated according to the peak area relative to that of the internal standard, whose concentration was constant.

Sensory Analysis. Five panelists (3 women and 2 men, aged from 25 to $38 \mathrm{yr}$ ), who were staff and graduate students of the Department of Food Science and Engineering in Beijing Technology and Business University (Beijing, China), performed sensory analysis. Each had at least $30 \mathrm{~h}$ of previous training on sensory analysis of dairy products using a method from 2 reports (Clare et al., 2005; Hedegaard et al., 2006). Six 30-min training sessions were held to focus on sensory properties in general and on similarities to whole milk flavor. Pasteurized whole milk and skim milk samples were used during training, as well as some of the experimental PCM and PCC. The training included smelling and tasting different dairy samples and discussing their characteristics. The panelists generated 8 descriptors and definitions in training sessions, along with reference materials for all of the descriptors (Table 2). For the purpose of the descriptive terminology used in this work, "aroma" refers to the specific aroma perceived when smelling the sample with the nostrils, and "flavor/ taste" refers to the flavor that is perceived retronasally when the sample is in the mouth.

The PCM and PCC were prepared within $3 \mathrm{~h}$ before every session and then kept in a $4^{\circ} \mathrm{C}$ refrigerator until 30 min before serving, when samples were tempered at room temperature. Cups were covered with plastic lids to preserve the aroma of samples. Samples $(20 \mathrm{~mL})$ were given to panelists monadically in $50-\mathrm{mL}$ plastic cups labeled with 2-digit numbers. Sensory references were given to panelists, who rinsed their mouths with spring water before evaluating every sample and expec-

Table 1. The optimized esterification conditions for better $\mathrm{PCM}$ and $\mathrm{PCC}^{1}$

\begin{tabular}{lcccc}
\hline Sample number & $\begin{array}{c}\text { Time } \\
(\mathrm{h})\end{array}$ & $\begin{array}{c}\text { Temperature } \\
\left({ }^{\circ} \mathrm{C}\right)\end{array}$ & $\begin{array}{c}\text { Lipase amount } \\
(\mathrm{U} / \mathrm{mL})\end{array}$ & $\begin{array}{c}\text { Ethanol volume } \\
(\mu \mathrm{L} / \mathrm{mL})\end{array}$ \\
\hline Better PCM & & & & 0.8 \\
1 & 1.5 & 35 & 0.8 & 0.8 \\
2 & 2 & 40 & 1.0 & 0.8 \\
3 & 2 & 35 & 0.8 & 1.0 \\
4 & 2 & 35 & 3.7 & 1.0 \\
Better PCC & & & 3.7 & 1.0 \\
1 & 1.5 & 55 & 3.7 & 1.0 \\
2 & 2 & 60 & 3.7 & 1.2 \\
3 & 2 & 55 & 55 & \\
4 & 2 & 55 & \\
\hline
\end{tabular}

${ }^{1} \mathrm{PCM}=$ recombined milk product composed of skim milk $(100 \mathrm{~mL})$ and whole upper layer from esterified whole milk $(25 \mathrm{~mL}) ; \mathrm{PCC}=$ recombined milk product composed of skim milk $(100 \mathrm{~mL})$ and upper layer $(2 \mathrm{~g})$ from esterified single cream. 
Table 2. Sensory descriptors, their definitions, and reference materials

\begin{tabular}{|c|c|}
\hline Descriptor & Definition (reference material) \\
\hline \multicolumn{2}{|l|}{ Aroma } \\
\hline Milk aroma & Intensity of aroma of milk (natural bovine whole milk) \\
\hline Sweet fruit aroma & Intensity of aroma of sweet fruit (natural bovine whole milk with $5 \%$ mixed $\mathrm{FAEE}^{1}$ ) \\
\hline Rancid aroma & $\begin{array}{l}\text { Intensity of aroma of rancidity (lipase-hydrolyzed whole milk or single cream } \\
\text { samples) }\end{array}$ \\
\hline \multicolumn{2}{|r|}{ (10 } \\
\hline Milk flavor & Intensity of milk flavor \\
\hline Sweet fruit flavor & Intensity of sweet fruit flavor \\
\hline Rancid flavor & Intensity of rancid flavor \\
\hline Bitter flavor & Intensity of bitter flavor \\
\hline \multicolumn{2}{|l|}{ Mouthfeel } \\
\hline Residual mouthfeel & Degree of product left in the mouth after expectoration \\
\hline
\end{tabular}

torated all water and samples afterward. Pasteurized whole milk from the same batch as PCM and PCC was available to the panelists at all times. The sensory descriptors and similarity degrees were all scored using 100-point scales, from 1 to $100(0-60=$ unqualified, no correlation of the descriptor or no flavor similarity to whole milk; $60-70=$ barely qualified, bare correlation of the descriptor or bare flavor similarity to whole milk; 70-80 = some qualified, some correlation of the descriptor or some flavor similarity to whole milk; 80-90 $=$ fairly qualified, fair correlation of the descriptor or fair flavor similarity to whole milk; $90-100=$ maximally qualified, maximum correlation of the descriptor or maximum flavor similarity to whole milk).

The PCM and PCC were served for preliminary sensory analysis in the process of single parameter optimizations of lipase esterification reactions. The sensory scores were based on overall impressions according to all the sensory reference by the panelists without scoring any single descriptor. Four better PCM (samples 1 to 4 ) and 4 better PCC (samples 1 to 4 ) were selected after the preliminary sensory evaluation.

During the descriptive sensory analysis of the 4 better PCM and 4 better PCC, the panelists attended 6 sessions (one morning session every day) for a 6 -d period. Four samples were served at every session. The order of the samples was randomized for the panelists over every 2-d period, which corresponded to a replicate. There were 3 replicate evaluations (one per $2 \mathrm{~d}$ ), with all 8 samples $(2$ recombined milk types $\times 4$ better conditions) served within every replicate. The criterion of descriptive sensory evaluation was emphasized on the descriptors in general, which accounted for $80 \%$ of a total sensory score, and the similarity to natural whole milk flavor accounted for 20\%. The O-PCM and OPCC were selected after the descriptive sensory evaluation. The sensory score was performed according to the following equations:

$$
\begin{gathered}
\text { Sensory score }=80 \% \mathrm{D}+20 \% \mathrm{~S}, \\
\mathrm{D}=\frac{\sum_{i=1}^{m} \mathrm{D}_{i}}{\mathrm{~m}}, \\
\mathrm{D}_{i}=\frac{\sum_{j=1}^{n} \mathrm{Fd}}{\mathrm{n}}, \\
\mathrm{S}=\frac{\sum_{i=1}^{n} \mathrm{~S}_{i}}{\mathrm{n}},
\end{gathered}
$$

where $\mathrm{D}$ is the sensory score of descriptors of a sample (better PCM or better PCC), accounting for $80 \%$ as the primary evaluation requirement; $\mathrm{S}$ is the score of flavor similarity to natural whole milk of a sample, accounting for $20 \%$ as the high-level requirement; $\mathrm{D}_{i}$ is the sensory score from a descriptor by panelists of a certain sample; $\mathrm{Fd}_{j}$ is the sensory score from a descriptor by a panelist of a certain sample; $S_{i}$ is the similarity score of a certain sample evaluated by a panelist; $m$ is the number of the descriptors that were used to describe the samples ( $\mathrm{m}$ $=8: 3$ for aroma, 4 for flavor/taste, 1 for mouthfeel) among which the descriptors of milk and fruit aroma/ flavor and mouthfeel were evaluated by degree of acceptance, and the descriptors of rancid and bitter aroma/ flavor were evaluated by degree of tolerance; and $n$ is the number of the panelists $(\mathrm{n}=5)$.

Milk Compositional Analysis. The basic compositional values of O-PCM and O-PCC, accompanied by natural bovine whole milk and skim milk from the same batch samples, were measured using the milk composition analyzer (Foss MilkScan FT120, Hillerød, Denmark), the results of which are listed in Table 3. 
Table 3. The compositional values (SE in parentheses) of different milk samples

\begin{tabular}{|c|c|c|c|c|c|c|}
\hline Sample $^{1}$ & Fat $(\%)$ & Protein (\%) & Lactose (\%) & SNF (\%) & TS $(\%)$ & Density \\
\hline $\mathrm{O}-\mathrm{PCC}$ & $0.15(0.01)^{\mathrm{c}}$ & $3.44(0.05)^{\mathrm{a}}$ & $4.72(0.02)^{\mathrm{b}}$ & $9.11(0.03)^{\mathrm{a}}$ & $9.38(0.01)^{\mathrm{c}}$ & $1.036(0.001)^{\mathrm{a}}$ \\
\hline Natural whole milk & $3.72(0.01)^{\mathrm{a}}$ & $3.17(0.03)^{\mathrm{c}}$ & $4.53(0.02)^{\mathrm{d}}$ & $8.81(0.01)^{\mathrm{b}}$ & $12.52(0.02)^{\mathrm{a}}$ & $1.032(0.001)^{\mathrm{b}}$ \\
\hline
\end{tabular}

${ }^{\mathrm{a}-\mathrm{d}}$ Means in a column followed by different superscripts are different $(P<0.05)$.

${ }^{1} \mathrm{O}-\mathrm{PCM}$ and $\mathrm{O}-\mathrm{PCC}=\mathrm{PCM}$ and $\mathrm{PCC}$ acquired under optimal conditions. $\mathrm{PCM}=$ recombined milk product composed of skim milk $(100 \mathrm{~mL})$ and all upper layer from esterified whole milk $(25 \mathrm{~mL})$; PCC $=$ recombined milk product composed of skim milk $(100 \mathrm{~mL})$ and upper layer $(2$ g) from esterified single cream.

\section{Statistical Analysis}

All determinations were carried out in triplicate, and the experimental results were expressed as means (SE). Statistical analysis was performed by SPSS 22 (SPSS Inc., Chicago, IL). The results were considered significantly different at $P<0.05$.

\section{RESULTS AND DISCUSSION}

\section{HS-SPME Fiber Screening for Extraction of Milk Products}

Different SPME fibers have different selectivity when analyzing the same volatile profiles (Lin et al., 2013; Du et al., 2014). Five SPME fibers (75- $\mu \mathrm{m}$ CAR/PDMS, 85- $\mu \mathrm{m}$ PA, 100- $\mu \mathrm{m}$ PDMS, 65- $\mu \mathrm{m}$ PDMS/DVB, and 50-/30- $\mu \mathrm{m}$ DVB/CAR/PDMS) were screened to analyze the volatile components of whole milk to determine which fiber(s) was/were preferable for extraction of milk volatiles.

As shown in Figure 2, the 75- $\mu \mathrm{m}$ CAR/PDMS and $85-\mu \mathrm{m}$ PA fibers exhibited higher sensitivity for amount and type of volatile components among the 5 fibers. For 75- $\mu \mathrm{m}$ CAR/PDMS, 11 volatiles and 5 fatty acids were extracted, the total amounts of which were 0.0873 and $0.0118 \mu \mathrm{g} / \mathrm{L}$, respectively. The $85-\mu \mathrm{m}$ PA resulted in 7 volatiles and 5 fatty acids, amounting to 0.0232 and $0.0216 \mu \mathrm{g} / \mathrm{L}$, respectively. Therefore, we inferred that the $75-\mu \mathrm{m}$ CAR/PDMS fiber better suited to reveal the total volatile profile of milk samples and the $85-\mu \mathrm{m}$ PA fiber was capable of detecting VFA in a relatively specific way. Therefore, the $75-\mu \mathrm{m}$ CAR/PDMS fiber was used to monitor the variation of volatile profiles in milk samples.

\section{Optimization of Lipase-Catalyzed Reactions of Whole Milk}

Lipase Hydrolysis Reaction. In this part, we optimized the parameters hydrolysis temperature $(30,35$, 40,45 , and $\left.50^{\circ} \mathrm{C}\right)$, hydrolysis time $(0.5,1,2,3,4,5$, and
$6 \mathrm{~h})$, and lipase loading $(0.2,0.4,0.6,0.8,1.0$, and 1.2 $\mathrm{U} / \mathrm{mL}$ ), as shown in Figure 3.

From the HS-SPME-GC-MS and AV results, when the temperature increased, the amount of whole volatile compounds and fatty acids initially increased because of the hydrolysis effect of lipase, reaching a maximum level at $35^{\circ} \mathrm{C}$, but then the volatile substances began to transform and degrade, resulting in a decrease in amount and then reaching a state of balance (Contarini et al., 1997; Perreault et al., 2010). When the reaction time was extended, volatiles increased and reached a maximal level in $4 \mathrm{~h}$, and then diminished slightly until reaching a plateau around $6 \mathrm{~h}$. When lipase loading was added, the trend in variation was similar to that of time. Thus, the optimized conditions for lipase hydrolysis were $35^{\circ} \mathrm{C}$ for $4 \mathrm{~h}$ using $1.0 \mathrm{U} / \mathrm{mL}$ Palatase $20000 \mathrm{~L}$.

Under the effect of lipase hydrolysis, the proportion of VFA accounted for over $90 \%$ of the total volatile compounds discovered from HS-SPME-GC-MS, which indicates that Palatase 20000L could release sufficient VFA at the $s n-1$ and $s n-3$ positions in the TAG from milk fat.

Lipase Esterification Reaction. The parameters of esterification temperature $(35,40,45,50,55$, and $\left.60^{\circ} \mathrm{C}\right)$, esterification time $(0.5,1.0,1.5,2.0,2.5$, and 3.0 $\mathrm{h})$, lipase loading $(0,0.2,0.4,0.6,0.8,1.0$, and $1.2 \mathrm{U} /$ $\mathrm{mL})$, and ethanol volume $(0,0.4,0.6,0.8,1.0,1.2$, and $1.4 \mu \mathrm{L} / \mathrm{mL}$ ) of esterification reaction were optimized, as illustrated in Figure 4.

The yield of the total volatile compounds and fatty acids peaked at $40^{\circ} \mathrm{C}$. Yield of volatile compounds increased when the reaction was prolonged, with the greatest yield achieved after $1.5 \mathrm{~h}$.

For lipase loading, most volatile compounds were generated when $0.8 \mathrm{U} / \mathrm{mL}$ of lipase was added. When the amount of lipase was higher than $0.8 \mathrm{U} / \mathrm{mL}$, the total volatiles decreased because of the possible transformation and degradation. Meanwhile, the sensory score of PCM was highest when the lipase loading was $1.0 \mathrm{U} / \mathrm{mL}$. The amount of free ethanol remained nearly unchanged, which might be due to an instant mechanism of synthesis and decomposition of FAEE. 
As more ethanol was added, production of total volatile compounds, including FAEE, increased, whereas SCFA and free ethanol remained almost unchanged when ethanol concentration was greater than $0.4 \mu \mathrm{L} /$ $\mathrm{mL}$. As can be seen in Figure 4, the fatty acids from hydrolysis were able to create FAEE continuously when more ethanol was added. The more FAEE produced, the more thoroughly the milk fat decomposed, releasing more fatty acids to become FAEE and reducing the

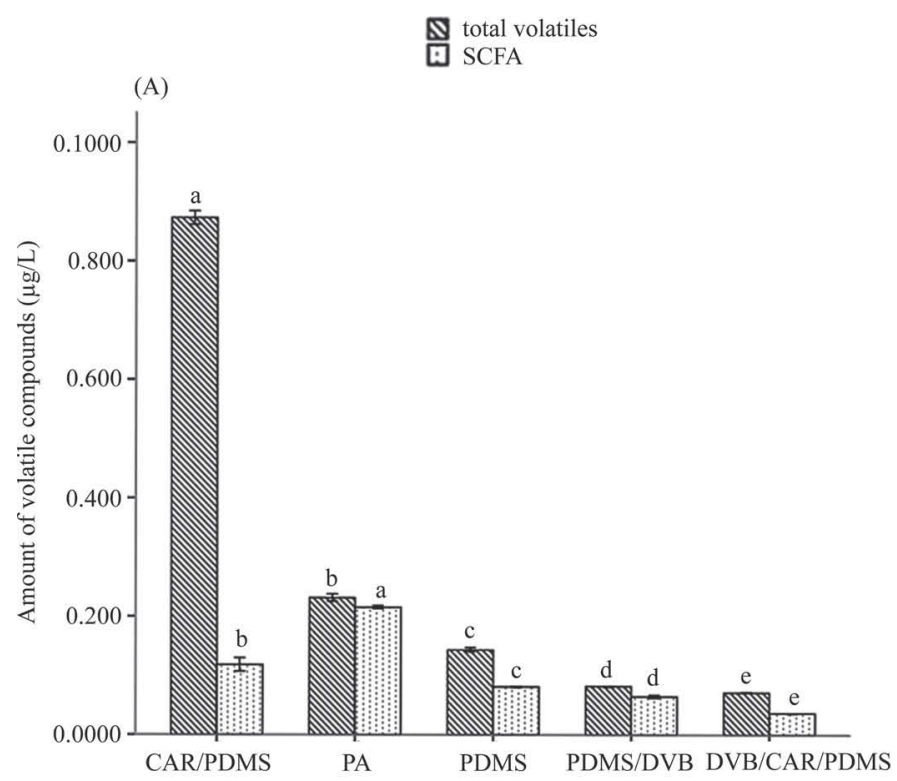

(B)

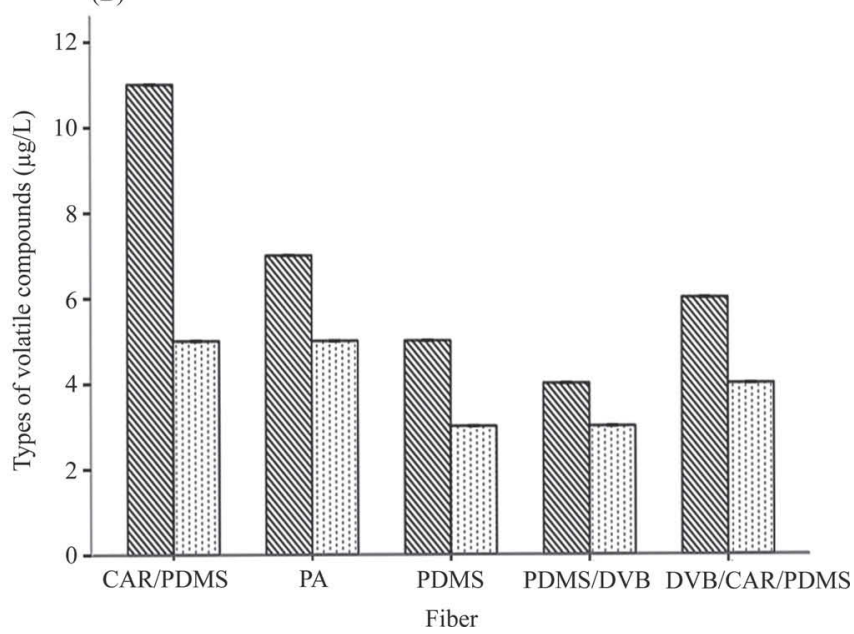

Figure 2. Comparison of amounts (A) and types (B) of volatile compounds from whole milk extracted by 5 types of solid-phase microextraction fiber $[75-\mu \mathrm{m}$ carboxen/PDMS (CAR/PDMS), 85- $\mu \mathrm{m}$ polyacrylate (PA), 100- $\mu \mathrm{m}$ polydimethylsiloxane (PDMS), 65- $\mu \mathrm{m}$ PDMS/ divinylbenzene (PDMS/DVB), and 50-/30- $\mathrm{m} \mathrm{DVB/CAR/PDMS;} \mathrm{all}$ from Supelco Inc., Bellefonte, PA]. Means within a group [total volatiles or short-chain fatty acids (SCFA)] followed by different letters $(\mathrm{a}-\mathrm{e})$ are different $(P<0.05)$. Error bars represent SE. amounts of fat in the milk samples to lower levels. However, too much FAEE would harm milk flavor because of the excessive fruit aroma.

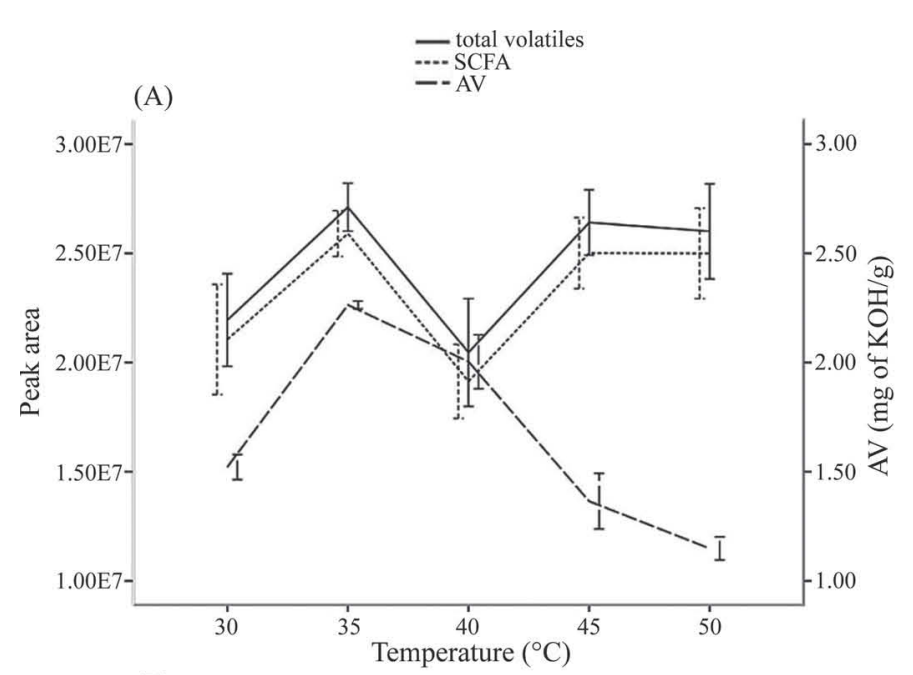

(B)

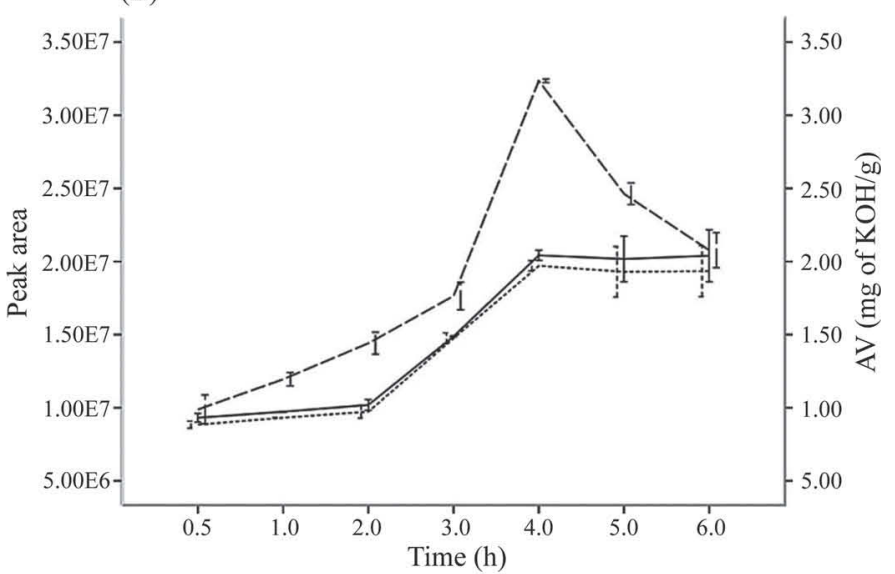

(C)

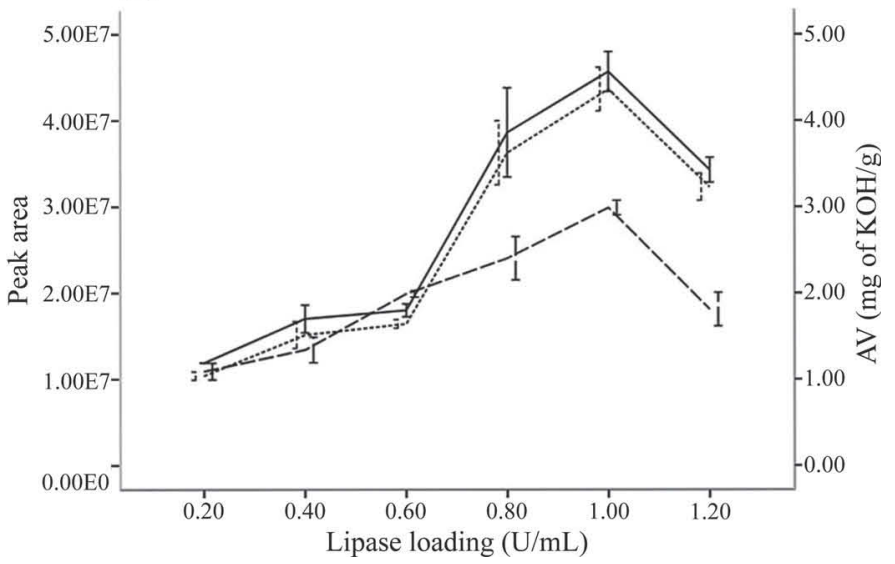

Figure 3. The amount variation of volatile compounds and fatty acids from the whole milk samples in different conditions of temperature (A), time (B), and lipase loading (C). AV = acid value; $\mathrm{SCFA}=$ short-chain fatty acid. Error bars represent SE. 
(A)

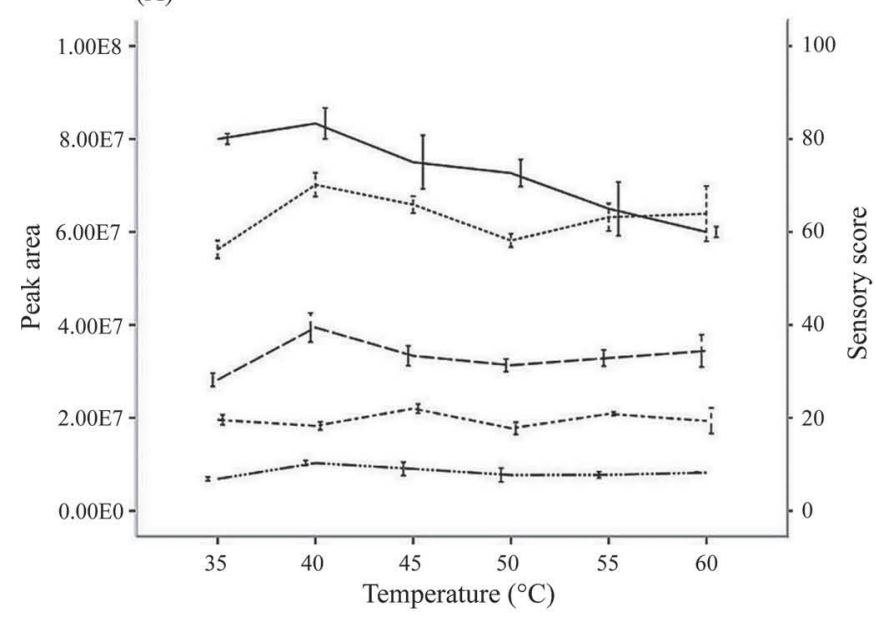

(B)

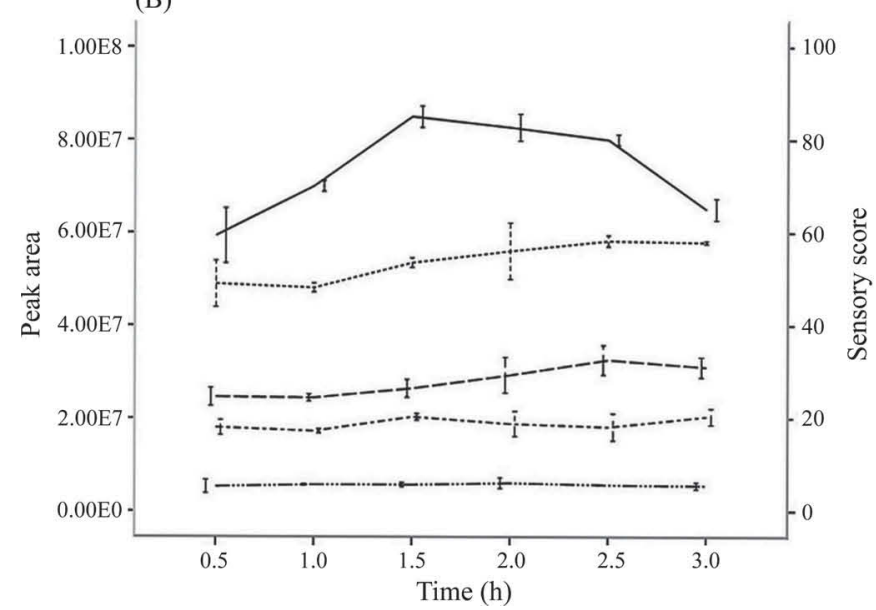

(C)

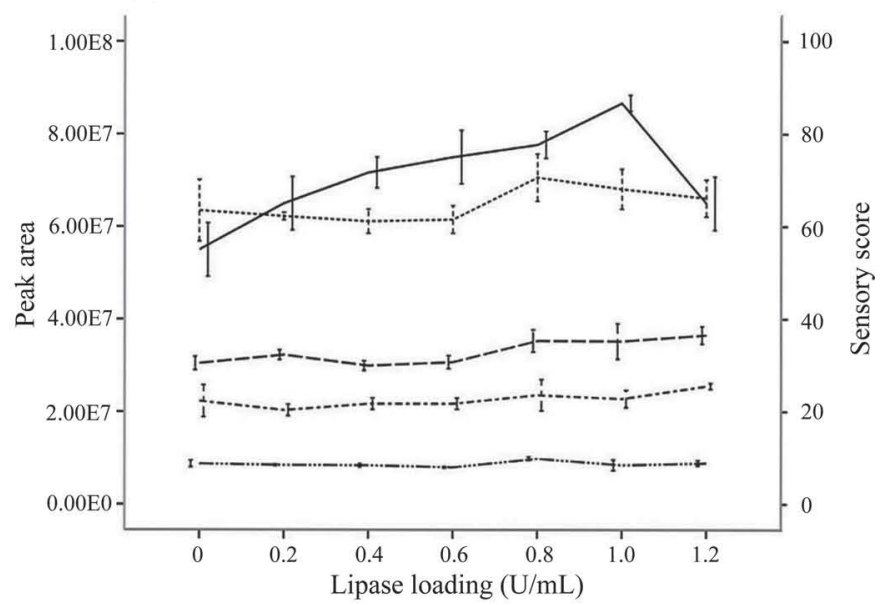

(D)

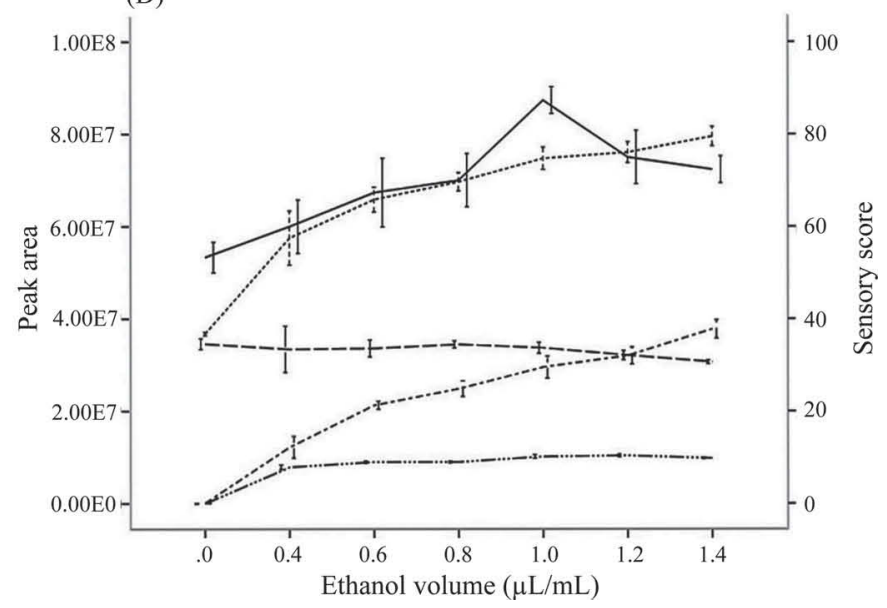

Figure 4. The variation of the volatile compound amounts and the sensory scores of the esterified whole milk samples in different conditions of temperature (A), time (B), lipase loading (C), and ethanol volume (D). FAEE = fatty acid ethyl ester; SCFA = short-chain fatty acid. Error bars represent SE.

When all 4 esterification conditions (Table 1) and sensory scores (Table 4) were taken into consideration, the O-PCM esterification condition (i.e., the better PCM sample 3 condition) was $35^{\circ} \mathrm{C}, 2 \mathrm{~h}$, Palatase 20000L of $1.0 \mathrm{U} / \mathrm{mL}$, ethanol $0.8 \mu \mathrm{L} / \mathrm{mL}$.

\section{Optimization of Lipase-Catalyzed Reaction of Single Cream}

Lipase Hydrolysis Reaction. We compared the influences of hydrolysis temperature $(30,35,40,45,50$, 55 , and $\left.60^{\circ} \mathrm{C}\right)$, hydrolysis time $(1,2,3,4,5$, and $6 \mathrm{~h})$, and lipase loading $(1.10,2.20,2.65,3.30,3.75,4.40$, and $5.50 \mathrm{U} / \mathrm{mL}$ ) when single cream was hydrolyzed by lipase, as shown in Figure 5.
The amount of volatile compounds peaked at $50^{\circ} \mathrm{C}$. In addition, addition of $3.30 \mathrm{U} / \mathrm{mL}$ of Palatase $20000 \mathrm{~L}$ resulted in peak yield of volatile compounds.

With respect to the influence of hydrolysis time, a decline of volatile compounds was observed before $3 \mathrm{~h}$ by HS-SPME-GC-MS, which might be due to the relatively high fat proportion of single cream. The stronger interactions of milk fat globules and the greater protective effect of milk fat globule membranes resulted in a longer lag time before the successful contact with and catalysis of the inner milk fat by Palatase $20000 \mathrm{~L}$ (Lopez, 2011; Bourlieu et al., 2012). Meanwhile, the effect of heating induces the diffusion and transformation of the existing volatile components, which causes an illusion that the amount of volatiles is decreasing 
(Méndez-Velasco and Goff, 2012). After $3 \mathrm{~h}$, the increase indicated that the TAG of milk fat began to be rapidly hydrolyzed to produce more volatiles and then maintained a state of stable maximum around 4 and $5 \mathrm{~h}$. However, because a longer time of reaction could

(A)

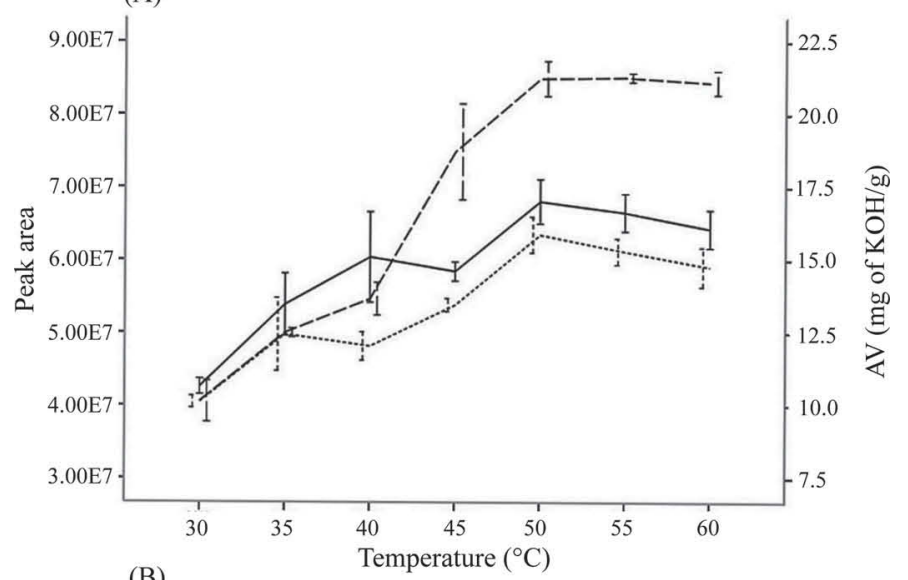

(B)

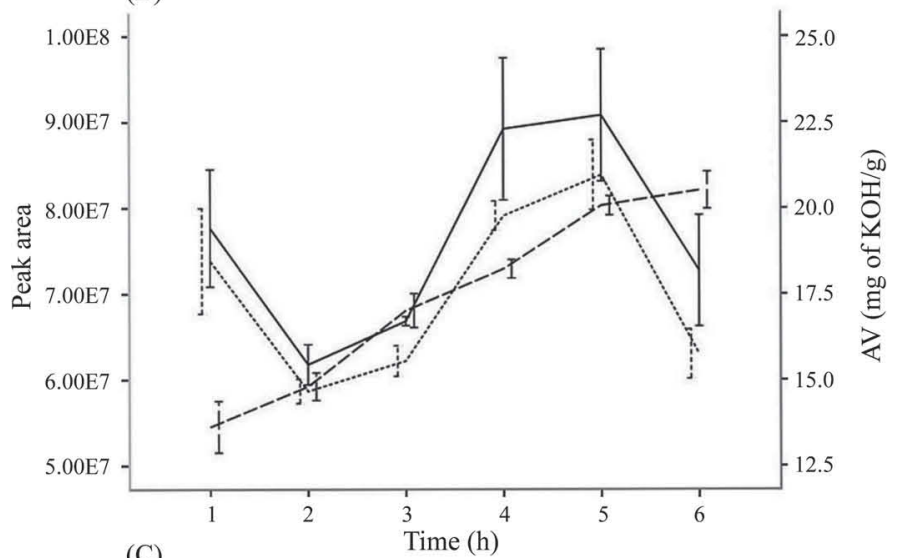

(C)

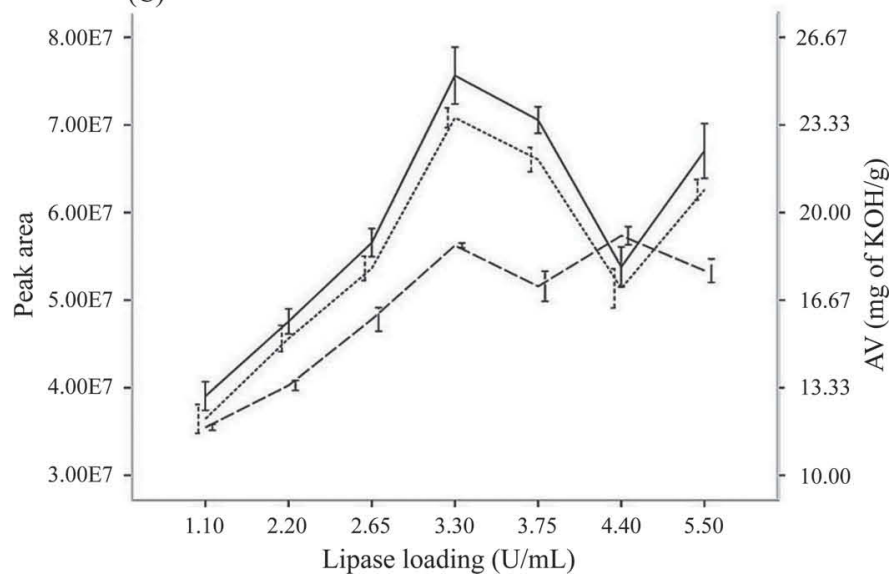

Figure 5. The variation in amount of volatile compounds and fatty acids from single cream samples under different conditions of temperature (A), time (B), and lipase loading (C). AV = acid value; SCFA = short-chain fatty acid. Error bars represent SE.

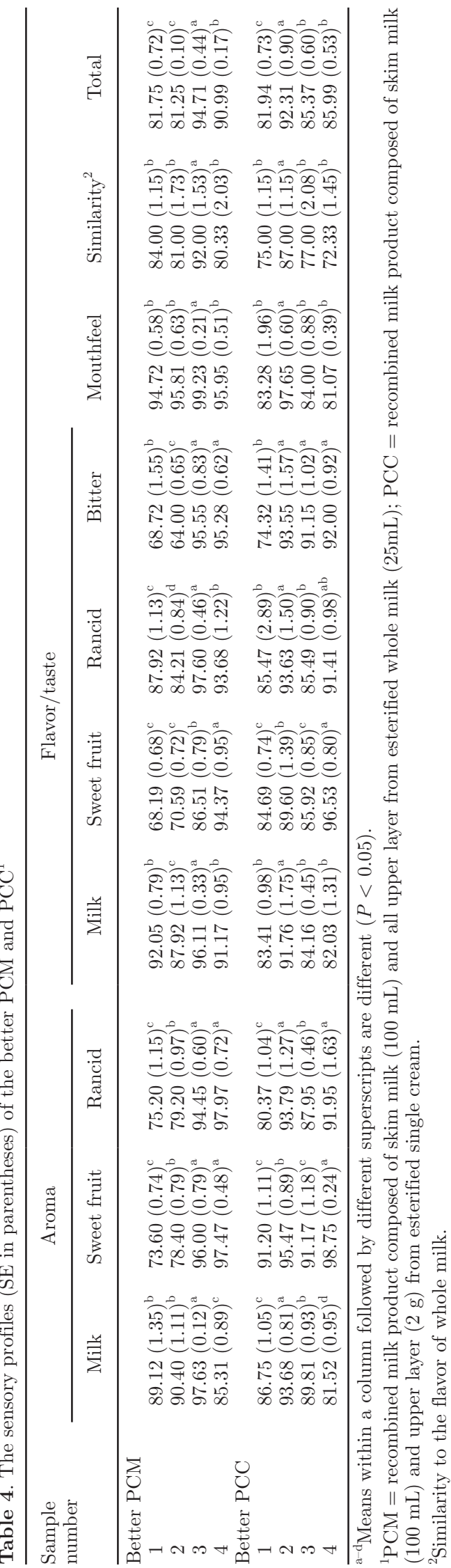

Journal of Dairy Science Vol. 99 No. 11, 2016 


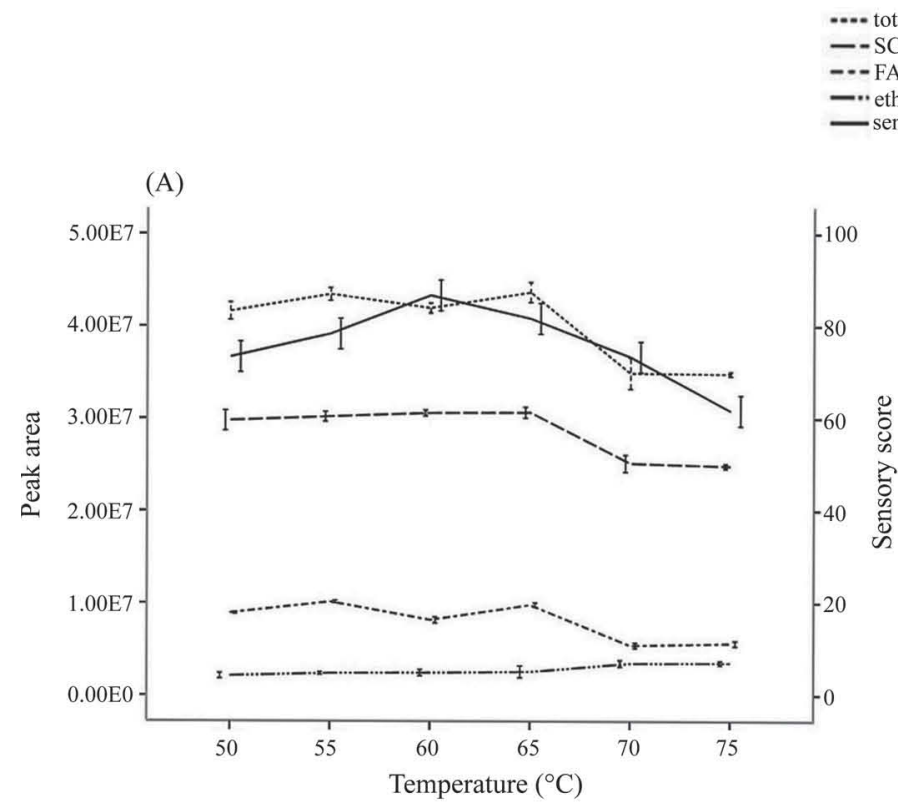

...- total volatiles

- SCFA

-* ethano

- sensory score

(A)

(B)

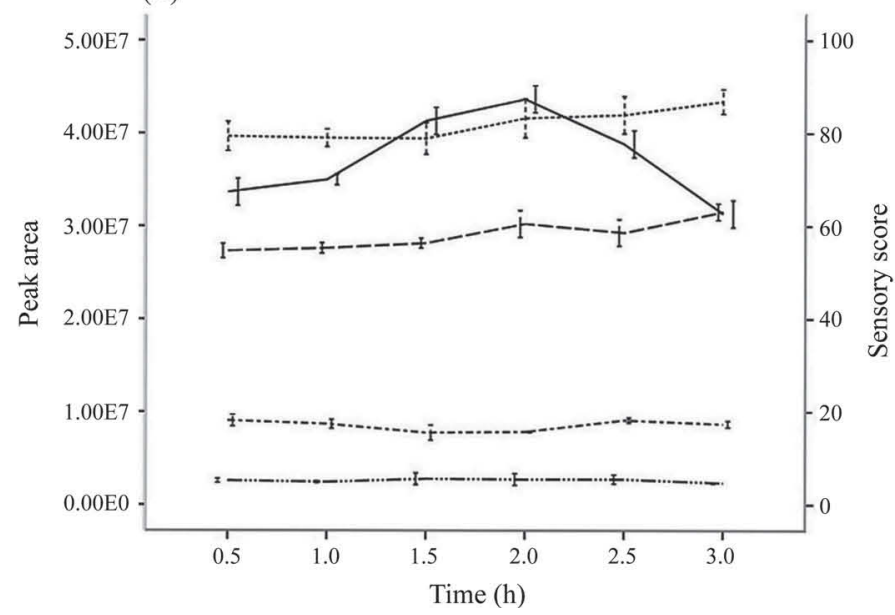

(C)

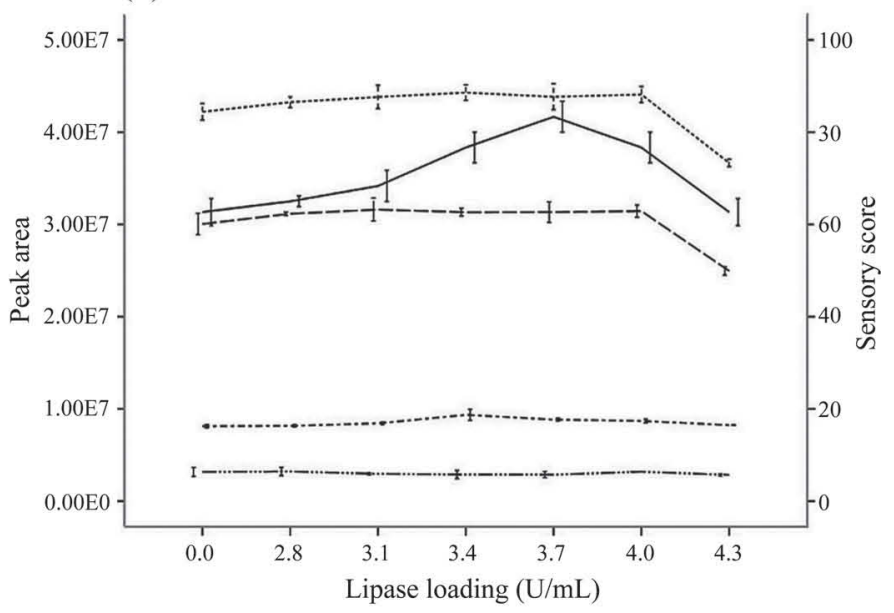

(D)

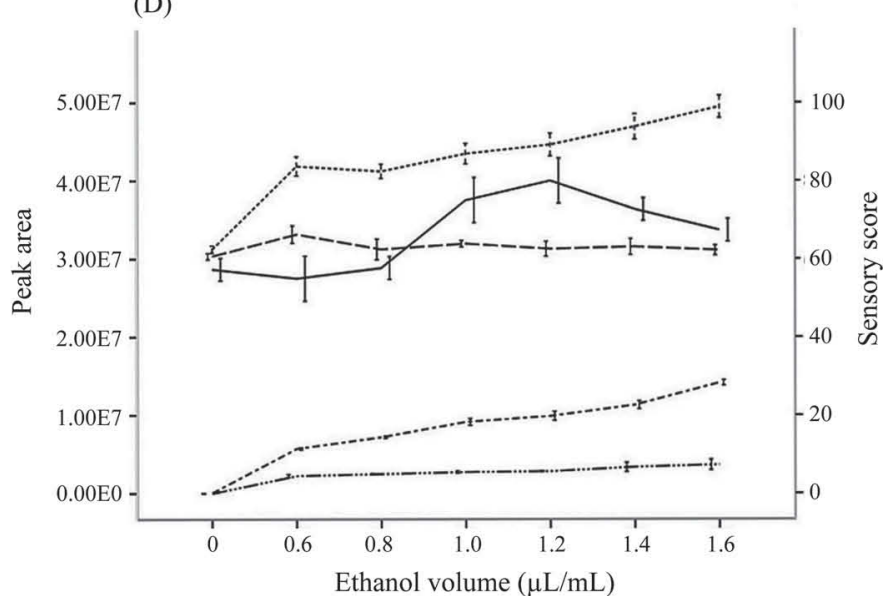

Figure 6. The variation in amount of volatile compounds and sensory scores of esterified single cream samples under different conditions of temperature (A), time (B), lipase loading (C), and ethanol volume (D). FAEE = fatty acid ethyl ester; SCFA = short-chain fatty acid. Error bars represent SE.

trigger unfavorable side effects, for the following reaction, $4 \mathrm{~h}$ was chosen.

Lipase Esterification Reaction. We compared esterification temperature $\left(50,55,60,65,70\right.$, and $\left.75^{\circ} \mathrm{C}\right)$, esterification time $(0.5,1.0,1.5,2.0,2.5$, and $3.0 \mathrm{~h})$, lipase loading $(0,2.8,3.1,3.4,3.7,4.0$, and $4.3 \mathrm{U} / \mathrm{mL})$, and ethanol volume $(0,0.6,0.8,1.0,1.2,1.4$, and 1.6 $\mu \mathrm{L} / \mathrm{mL}$ ) of the lipase esterification reaction, as shown in Figure 6.

Production of total volatile components, including fatty acids, increased with increasing temperature until $65^{\circ} \mathrm{C}$. The amounts of FAEE and ethanol were nearly unchanged, whereas the sensory scores of PCC were changed when temperature increased, indicating that the esterification of fatty acids with ethanol was carried on in a nearly balanced variation. At temperatures greater than $65^{\circ} \mathrm{C}$, amounts of total volatiles, SCFA, and FAEE were less, whereas ethanol was greater. This might be due to the occurrence of new types of reactions when temperature increased, such as oxidation of milk fat, degeneration of milk protein, or the Maillard reaction (Contarini et al., 1997; Shahidi and Zhong, 2010; Waraho et al., 2011), indicating that undesirable side reactions were very likely taking place. Therefore, $60^{\circ} \mathrm{C}$ was chosen for further experiments. When it came to the influence of esterification time, lipase loading, 
and ethanol volume, the shift mechanisms were a lot like the variation trends of lipase esterification reactions of whole milk.

When all 4 esterification conditions (Table 1) and sensory scores (Table 4) were taken into consideration, the O-PCC esterification condition (i.e., the better PCC sample 2 condition) was $60^{\circ} \mathrm{C}, 2 \mathrm{~h}$, Palatase 20000L 3.7 $\mathrm{U} / \mathrm{mL}$, and ethanol $1.0 \mu \mathrm{L} / \mathrm{mL}$.

\section{Sensory Analysis}

The sensory profiles of 4 better PCM and 4 better PCC (Table 1) are described in Table 4. Among the better PCM, sample 1 was lacking sweet fruit aroma and taste $(P<0.05)$ with rather more rancid aroma and bitter taste. The poor sweet fruit aroma and taste were caused by short esterification time, which reduced the synthesis of FAEE. Rancid aroma and bitter taste can occur not only due to lipolysis and proteolysis, but also due to interactions with other components such as calcium phosphate during heat and catalysis treatments (Olabi et al., 2015). Sample 2 had deficient milk flavor $(P<0.05)$ with unpleasant rancid and bitter taste because of the higher esterification temperature, which might have led to greater decomposition of milk fat and protein. Sample 3 had more milk aroma and taste $(P<0.05)$ and less $(P<0.05)$ rancid and bitter flavor than the other 3 better PCM samples. The mouthfeel of sample 3 was scored the highest $(P<0.05)$, which could be interpreted as favorable acceptance of homogeneity and fluidity by the panelists (Bruzantin et al., 2016). Sample 4 possessed more sweet fruit aroma and taste $(P<0.05)$ because of high-level FAEE synthesis with more ethanol, which, however, weakened the intensity of milk flavor and negatively influenced the similarity to whole milk flavor. Because of its high total sensory score $(P<0.05)$, sample 3 was selected as the $\mathrm{O}-\mathrm{PCM}$ for further analysis.

Among the better PCC, sample 1 had more rancid aroma and bitter flavor $(P<0.05)$ with less sweet fruit aroma and taste for insufficient synthesis of FAEE. Sample 2 had high sensory scores $(P<0.05)$ in the acceptance of milk aroma and taste, mouthfeel, and similarity to the flavor of whole milk, as well tolerance of rancid and bitter flavor, which indicated that some higher temperatures might benefit the sensory performance of PCC. Sample 3 did not differ from other better PCC in any of the sensory descriptors, which also showed poor similarity to whole milk flavor. Sample 4 possessed high intensity of sweet fruit aroma and taste $(P<0.05)$, which masked the unpleasant rancid and bitter flavor but also the advantageous milk aroma, resulting in a negative mouthfeel and low similarity to whole milk flavor. Based on its high total sensory score $(P<0.05)$, sample 2 was selected as the O-PCC for further analysis.

Of the O-PCM and O-PCC, both were considered to have favorable milk flavor by the panelists; however, the mouthfeel was not mellow enough, probably because of the low level of milk fat. The O-PCM had a higher score of similarity to whole milk flavor and a higher total sensory score, indicating that it was closer to a realistic whole milk flavor. Meanwhile, O-PCC had a more intensity of sweet fruit aroma and flavor derived from the greater FAEE, which lowered its similarity to whole milk flavor. However, the output quantity of the PCC from catalyzed single cream was higher than that of PCM from catalyzed whole milk. Hence, in consideration of efficiency, further research would be beneficial to try to improve the PCC flavor to be more realistic to natural whole milk.

\section{Analysis of Volatiles of the Recombined Milk Products by HS-SPME-GC-MS}

The volatile profiles of O-PCM and O-PCC were investigated by HS-SPME-GC-MS, selecting the 75$\mu \mathrm{m}$ CAR/PDMS and $85-\mu \mathrm{m}$ PA SPME fibers, and the results are reported in Table 5 .

The main volatiles were SCFA, FAEE, methyl ketones (2-ketones), and other substances, such as hexanal, dimethyl sulfone, and $\delta$-decalactone. The SCFA were mostly released from the hydrolysis of TAG from milk fat, the flavor thresholds of which were low, indicating that the amount and composition of SCFA have a significant influence on the quality of milk flavor. Among them, butyric acid and caproic acid were the key flavor components in milk, which affect milk flavor when present in normal concentrations (Lencki et al., 1998; Biolatto et al., 2007). Caprylic acid and capric acid, having oily and waxy aromas, were also typical substances affecting milk flavor. Although many other kinds of volatile compounds had been reported in bovine milk products, such as aldehydes, ketones, sulfur, and nitrogenous substances (Forss, 1971; Schwambach and Peterson, 2006; Vazquez-Landaverde et al., 2006; Miao et al., 2009; Pan et al., 2014; Ai et al., 2015), volatile SCFA are still relatively more frequent in existence and more characteristic in the volatiles stemming from milk fat. The FAEE mostly came from the esterification reaction with ethanol, providing a compensating lightly fruity and sweet flavor for the comparatively excessive SCFA (Holland et al., 2005). Methyl ketones were likely synthesized from the serial reactions of $\beta$-oxidation of saturated fatty acids, many of which also have an effect on milk flavor, such as 2-heptanone and 2-nona- 


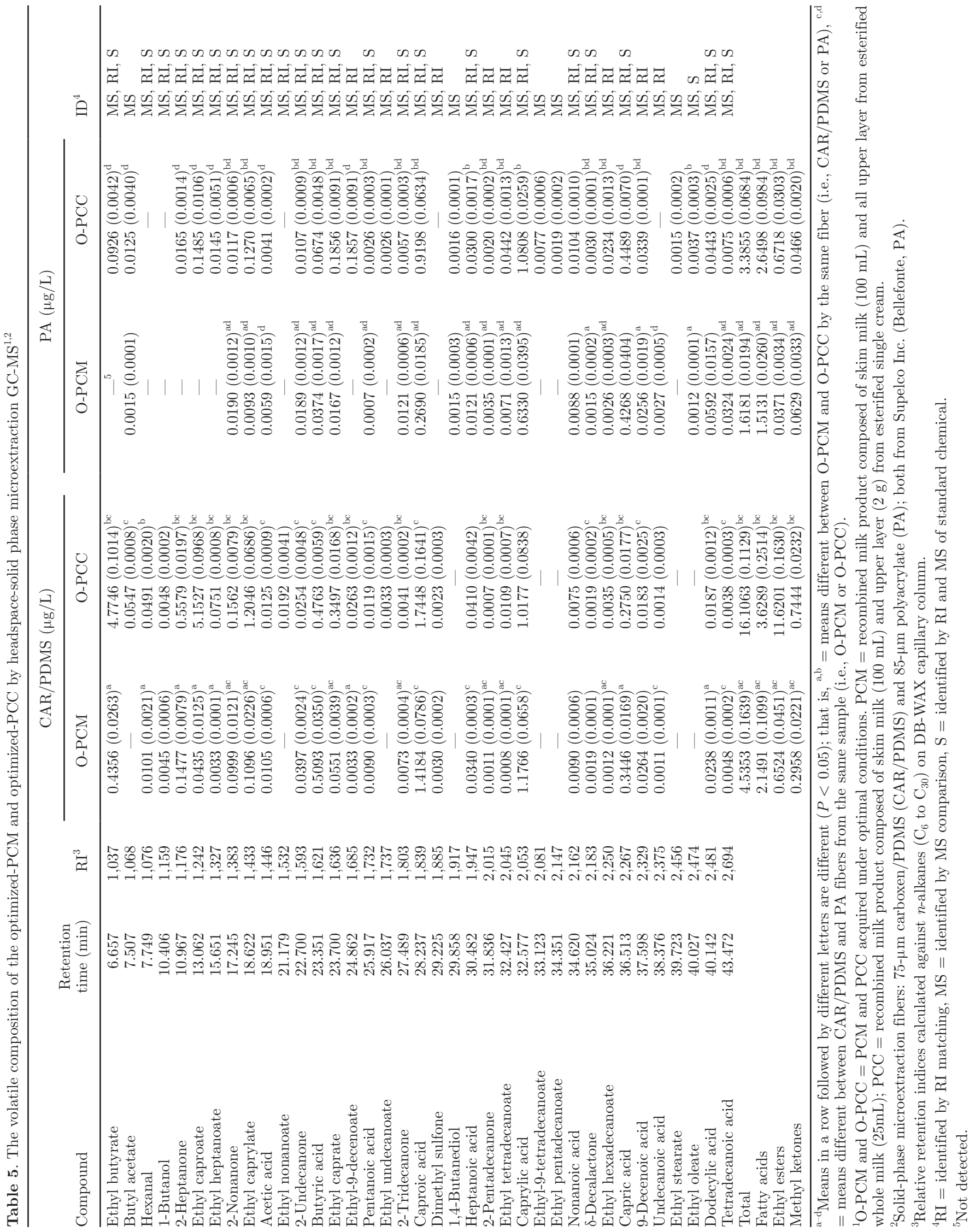


none, which possess an odor of cream and sweetness (Vazquez-Landaverde et al., 2005; Licón et al., 2012). $\delta$-Decalactone might be derived from the oxidation of lactose by heat treatment (Colahan-Sederstrom and Peterson, 2005). In addition, the detected hexanal and dimethyl sulfone may derive from the skim milk itself or might be secondary or tertiary oxidation products from the milk fat oxidation (Shiratsuchi et al., 1994; Valero et al., 2001).

From the $75-\mu \mathrm{m}$ CAR/PDMS fiber, the most abundant type of volatiles were SCFA and FAEE in O-PCM, whereas we found the opposite in O-PCC; the amount of methyl ketones differed only slightly in the 2 recombined products. From the $85-\mu \mathrm{m}$ PA SPME fiber, SCFA were the most abundant in both products, followed by FAEE and methyl ketones. These results reflect the different sensitivities of the 2 fiber coatings (Zhang et al., 2012).

By comprehensively analyzing the volatiles from OPCM and O-PCC by the 2 SPME fibers, we noted that more FAEE were present in O-PCC than in O-PCM, at levels exceeding that of SCFA. Furthermore, the amount of total volatile compounds was more abundant in O-PCC than in O-PCM. The reason for these find-

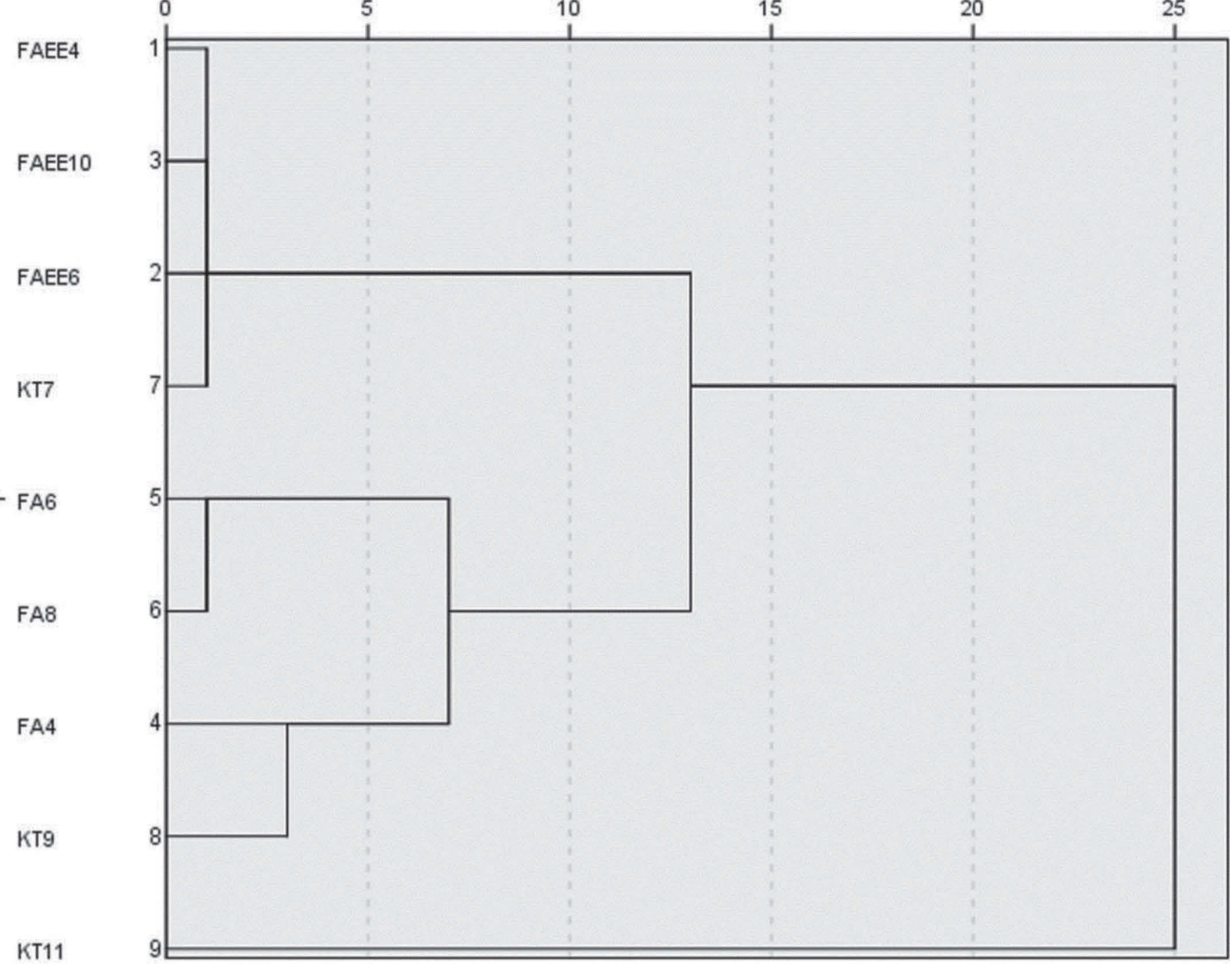

Figure 7. Cluster analysis of the volatile compounds of the O-PCM and O-PCC analyzed by headspace solid-phase microextraction (HSSPME) GC-MS: the types of volatiles were considered as the dependent variables. O-PCM and O-PCC $=$ PCM and PCC acquired under optimal conditions. Short-chain fatty acids: FA $4=$ butyric acid; FA $6=$ caproic acid; FA $8=$ caprylic acid. FAEE: FAEE4 = ethyl butyrate; FAEE6 = ethyl caproate; FAEE10 = ethyl caprate; methyl ketones: KT7 $=$ 2-heptanone; KT9 = 2-nonanone; KT11 = 2-undecanone. 
ings may be of the higher content of milk fat in single cream, which allowed greater generation of volatiles, including FAEE when enough ethanol was available.

\section{Cluster Analysis}

Clustering is a commonly used method in many scientific fields dealing with original data, and it assists researchers in identifying groups of similar characteristics (Goyeneche et al., 2014; Liu et al., 2014). In this study, cluster analysis was applied to show compositional differences in volatile profiles between the O-PCM and OPCC. The top 3 types in amount, among the respective volatile categories of SCFA, FAEE, and methyl ketones, were selected for cluster analysis.

As shown in Figure 7, 4 clusters were identified, indicating that significant differences were present in the volatile profiles of the O-PCM and O-PCC. Moreover, cluster analysis suggested that the types of volatile compounds exhibited significance for the aroma features. The FAEE had similar diversity of flavor within its category, whereas SCFA and methyl ketones exhibited different diversities within their own category, and the integrative analysis beyond one certain category of volatile components probably provided more information about the understanding and evaluation of the $\mathrm{O}-\mathrm{PCM}$ and O-PCC.

\section{CONCLUSIONS}

The lipase Palatase 20000L was able to catalyze whole milk and single cream to produce substantial amounts of volatile substances, especially SCFA and FAEE, with ethanol. The lipase reactions of hydrolysis and esterification were implemented to improve the flavor quality of the recombined skim milk products according to sensory evaluation. The synthesized FAEE had the potential to maintain the flavor quality of liquid dairy products in a suitable proportion. This work could provide a novel approach to modify the volatile profiles and potentially improve the sensory quality of skim milk products in a nonsynthetic and simplified way.

\section{ACKNOWLEDGMENTS}

This work was supported by a grant from the National High Technology Research and Development Program of China (863 Program) (No. 2011AA100903), the Importation and Development of High-Caliber Talents Project of Beijing Municipal Institutions (CIT\&TCD20130309 and IDHT20130506).

\section{REFERENCES}

Ai, N.-S., H.-L. Liu, J. Wang, X.-M. Zhang, H.-J. Zhang, H.-T. Chen, M.-Q. Huang, Y.-G. Liu, F.-P. Zheng, and B.-G. Sun. 2015. Triplechannel comparative analysis of volatile flavour composition in raw whole and skim milk via electronic nose, GC-MS and GC-O. Anal. Methods 7:4278-4284.

Biolatto, A., G. Grigioni, M. Irurueta, A. M. Sancho, M. Taverna, and N. Pensel. 2007. Seasonal variation in the odour characteristics of whole milk powder. Food Chem. 103:960-967.

Bourlieu, C., S. Bouhallab, and C. Lopez. 2009. Biocatalyzed modifications of milk lipids: Applications and potentialities. Trends Food Sci. Technol. 20:458-469.

Bourlieu, C., F. Rousseau, V. Briard-Bion, M. N. Madec, and S. Bouhallab. 2012. Hydrolysis of native milk fat globules by microbial lipases: Mechanisms and modulation of interfacial quality. Food Res. Int. 49:533-544.

Bruzantin, F. P., J. L. P. Daniel, P. P. M. da Silva, and M. H. F. Spoto. 2016. Physicochemical and sensory characteristics of fatfree goat milk yogurt with added stabilizers and skim milk powder fortification. J. Dairy Sci. 99:3316-3324.

Campbell, R. E., and M. A. Drake. 2013. Invited review: The effect of native and nonnative enzymes on the flavor of dried dairy ingredients. J. Dairy Sci. 96:4773-4783.

Cao, M., L. M. Fonseca, T. C. Schoenfuss, and S. A. Rankin. 2014. Homogenization and lipase treatment of milk and resulting methyl ketone generation in blue cheese. J. Agric. Food Chem. 62:57265733.

Clare, D., W. Bang, G. Cartwright, M. Drake, P. Coronel, and J. Simunovic. 2005. Comparison of sensory, microbiological, and biochemical parameters of microwave versus indirect UHT fluid skim milk during storage. J. Dairy Sci. 88:4172-4182.

Colahan-Sederstrom, P. M., and D. G. Peterson. 2005. Inhibition of key aroma compound generated during ultrahigh-temperature processing of bovine milk via epicatechin addition. J. Agric. Food Chem. 53:398-402.

Contarini, G., M. Povolo, R. Leardi, and P. M. Toppino. 1997. Influence of heat treatment on the volatile compounds of milk. J. Agric Food Chem. 45:3171-3177.

Du, L., J. Li, W. Li, Y. Li, T. Li, and D. Xiao. 2014. Characterization of volatile compounds of pu-erh tea using solid-phase microextraction and simultaneous distillation-extraction coupled with gas chromatography-mass spectrometry. Food Res. Int. 57:61-70.

Forss, D. 1971. The flavors of dairy fats-A review. J. Am. Oil Chem. Soc. 48:702-710.

Goyeneche, R., S. Roura, and K. Di Scala. 2014. Principal component and hierarchical cluster analysis to select hurdle technologies for minimal processed radishes. LWT Food Sci. Technol. (Campinas.) $57: 522-529$.

Hedegaard, R., D. Kristensen, J. H. Nielsen, M. B. Frøst, H. Østdal, J. E. Hermansen, M. Kröger-Ohlsen, and L. H. Skibsted. 2006. Comparison of descriptive sensory analysis and chemical analysis for oxidative changes in milk. J. Dairy Sci. 89:495-504.

Holland, R., S. Q. Liu, V. L. Crow, M. L. Delabre, M. Lubbers, M. Bennett, and G. Norris. 2005. Esterases of lactic acid bacteria and cheese flavour: Milk fat hydrolysis, alcoholysis and esterification. Int. Dairy J. 15:711-718.

Kalač, P., and E. Samková. 2010. The effects of feeding various forages on fatty acid composition of bovine milk fat: A review. Czech J. Anim. Sci. 55:521-537.

Karagül-Yüceer, Y., M. Drake, and K. Cadwallader. 2004. Evaluation of the character impact odorants in skim milk powder by sensory studies on model mixtures. J. Sens. Stud. 19:1-13.

Kurtovic, I., S. N. Marshall, M. R. Miller, and X. Zhao. 2011. Flavour development in dairy cream using fish digestive lipases from Chinook salmon (Oncorhynchus tshawytscha) and New Zealand hoki (Macruronus novaezealandiae). Food Chem. 127:1562-1568.

Lencki, R. W., N. Smink, H. Snelting, and J. Arul. 1998. Increasing short-chain fatty acid yield during lipase hydrolysis of a butterfat 
fraction with periodic aqueous extraction. J. Am. Oil Chem. Soc. 75:1195-1200.

Licón, C. C., J. Hurtado de Mendoza, L. Maggi, M. I. Berruga, R. M. Martín Aranda, and M. Carmona. 2012. Optimization of headspace sorptive extraction for the analysis of volatiles in pressed ewes' milk cheese. Int. Dairy J. 23:53-61.

Lin, L., M. Zhuang, F. Lei, B. Yang, and M. Zhao. 2013. GC-MS analysis of volatiles obtained by headspace solid-phase microextraction and simultaneous-distillation extraction from Rabdosia serra (MAXIM.) HARA leaf and stem. Food Chem. 136:555-562.

Liu, M.-Y., O. Tuzel, S. Ramalingam, and R. Chellappa. 2014. Entropy-rate clustering: Cluster analysis via maximizing a submodular function subject to a matroid constraint. IEEE Trans. Pattern Anal. Machine Intelligence 36:99-112.

Lock, A. L., and D. E. Bauman. 2004. Modifying milk fat composition of dairy cows to enhance fatty acids beneficial to human health. Lipids 39:1197-1206.

Lopez, C. 2011. Milk fat globules enveloped by their biological membrane: Unique colloidal assemblies with a specific composition and structure. Curr. Opin. Colloid Interface Sci. 16:391-404.

Lubary, M., G. W. Hofland, and J. H. ter Horst. 2010a. The potential of milk fat for the synthesis of valuable derivatives. Eur. Food Res. Technol. 232:1-8.

Lubary, M., G. W. Hofland, and J. H. ter Horst. 2010b. Synthesis and isolation of added-value milk fat derivatives using lipase-catalyzed reactions and supercritical carbon dioxide. Lipid Technol. 22:54-57.

Lubary, M., P. J. Jansens, J. H. ter Horst, and G. W. Hofland. 2010c. Integrated synthesis and extraction of short-chain fatty acid esters by supercritical carbon dioxide. AIChE J. 56:1080-1089.

Lubary, M., J. H. Ter Horst, G. W. Hofland, and P. J. Jansens. 2009. Lipase-catalyzed ethanolysis of milk fat with a focus on shortchain fatty acid selectivity. J. Agric. Food Chem. 57:116-121.

Méndez-Velasco, C., and H. D. Goff. 2012. Fat structure in ice cream: A study on the types of fat interactions. Food Hydrocoll. 29:152159.

Miao, H., S. Fan, Y.-N. Wu, L. Zhang, P.-P. Zhou, H.-J. Chen, Y.-F. Zhao, and J.-G. Li. 2009. Simultaneous determination of melamine, ammelide, ammeline, and cyanuric acid in milk and milk products by gas chromatography-tandem mass spectrometry. Biomed. Environ. Sci. 22:87-94.

Olabi, A., S. Jinjarak, R. Jimenez-Flores, J. H. Walker, and H. Daroub. 2015. Compositional and sensory differences of products of sweet-cream and whey buttermilk produced by microfiltration, diafiltration, and supercritical $\mathrm{CO}_{2}$. J. Dairy Sci. 98:3590-3598.

Pan, D. D., Z. Wu, T. Peng, X. Q. Zeng, and H. Li. 2014. Volatile organic compounds profile during milk fermentation by Lactobacillus pentosus and correlations between volatiles flavor and carbohydrate metabolism. J. Dairy Sci. 97:624-631.

Perreault, V., M. Britten, S. L. Turgeon, A. M. Seuvre, P. Cayot, and A. Voilley. 2010. Effects of heat treatment and acid-induced gelation on aroma release from flavoured skim milk. Food Chem. 118:90-95.

Regado, M. A., B. M. Cristóvão, C. G. Moutinho, V. M. Balcão, R. Aires-Barros, J. P. M. Ferreira, and F. Xavier Malcata. 2007. Flavour development via lipolysis of milkfats: Changes in free fatty acid pool. Int. J. Food Sci. Technol. 42:961-968.

Schwambach, S. L., and D. G. Peterson. 2006. Reduction of stale flavor development in low-heat skim milk powder via epicatechin addition. J. Agric. Food Chem. 54:502-508.

Shahidi, F., and Y. Zhong. 2010. Lipid oxidation and improving the oxidative stability. Chem. Soc. Rev. 39:4067-4079.

Shiratsuchi, H., M. Shimoda, K. Imayoshi, K. Noda, and Y. Osajima. 1994. Volatile flavor compounds in spray-dried skim milk powder. J. Agric. Food Chem. 42:984-988.

Shojaei, Z. A., R. S. T. Linforth, J. Hort, T. Hollowood, and A. J. Taylor. 2006. Measurement and manipulation of aroma delivery allows control of perceived fruit flavour in low- and regular-fat milks. Int J. Food Sci. Technol. 41:1192-1196.

Sun, J., B. Yu, P. Curran, and S. Q. Liu. 2012. Optimisation of flavour ester biosynthesis in an aqueous system of coconut cream and fusel oil catalysed by lipase. Food Chem. 135:2714-2720.

Sun, J., B. Yu, P. Curran, and S. Q. Liu. 2013. Lipase-catalysed ester synthesis in solvent-free oil system: Is it esterification or transesterification? Food Chem. 141:2828-2832.

Tan, H. S. G., B. Yu, P. Curran, and S. Q. Liu. 2011. Lipase-catalysed synthesis of natural aroma-active 2-phenylethyl esters in coconut cream. Food Chem. 124:80-84.

Valero, E., M. Villamiel, B. Miralles, J. Sanz, and I. Martınez-Castro. 2001. Changes in flavour and volatile components during storage of whole and skimmed UHT milk. Food Chem. 72:51-58.

Vazquez-Landaverde, P. A., J. Torres, and M. Qian. 2006. Quantification of trace volatile sulfur compounds in milk by solid-phase microextraction and gas chromatography-pulsed flame photometric detection. J. Dairy Sci. 89:2919-2927.

Vazquez-Landaverde, P. A., G. Velazquez, J. Torres, and M. Qian. 2005. Quantitative determination of thermally derived off-flavor compounds in milk using solid-phase microextraction and gas chromatography. J. Dairy Sci. 88:3764-3772.

Villeneuve, M.-P., Y. Lebeuf, R. Gervais, G. Tremblay, J. Vuillemard, J. Fortin, and P. Chouinard. 2013. Milk volatile organic compounds and fatty acid profile in cows fed timothy as hay, pasture, or silage. J. Dairy Sci. 96:7181-7194

Wang, B., and S. Xu. 2009. Effects of different commercial lipases on the volatile profile of lipolysed milk fat. Flavour Fragrance J. 24:335-340.

Waraho, T., D. J. McClements, and E. A. Decker. 2011. Mechanisms of lipid oxidation in food dispersions. Trends Food Sci. Technol. 22:3-13.

Zhang, S., L. Liu, D. Steffen, T. Ye, and D. Raftery. 2012. Metabolic profiling of gender: Headspace-SPME/GC-MS and 1H NMR analysis of urine. Metabolomics 8:323-334 